\title{
Cancer incidence appears to be rising in a small province in Islamic Republic of Iran: a population- based cohort study
}

M. Fararouei, ${ }^{1}$ Z. Parisai, ${ }^{2}$ M. Farahmand, ${ }^{3}$ R. Estakhrian Haghighi ${ }^{4}$ and M. Akbartabar Toori ${ }^{5}$

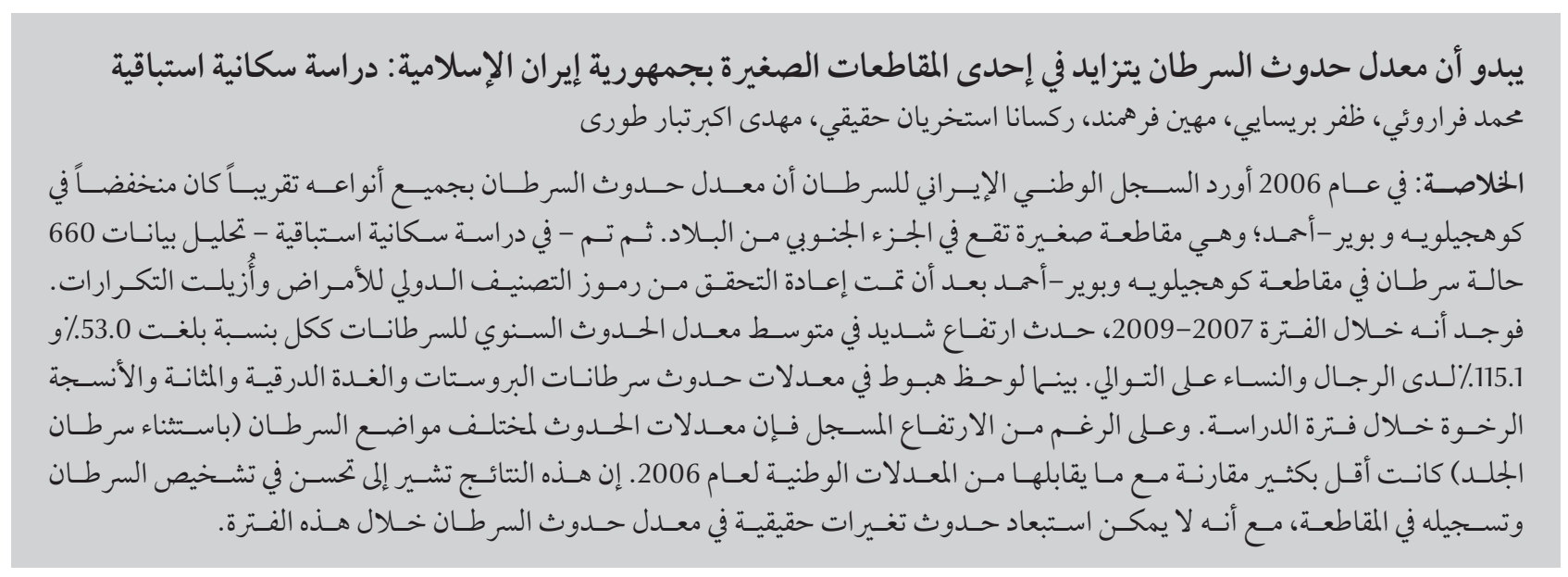

ABSTRACT In 2006 the Iranian national cancer registry reported that Kohgiluyeh and Boyer-Ahmad, a small province located in the southern part of the country, had a low incidence rate of almost all types of cancer. In a population-based cohort study, data on 660 cases of cancer in Kohgiluyeh and Boyer-Ahmad province were analysed after ICD codes had been rechecked and duplicates removed. Over the period 2007-2009 the annual average incidence rate of all cancers rose significantly by $53.0 \%$ and $115.1 \%$ in men and women respectively. Cancers of the prostate, thyroid, bladder and soft tissues decreased over the study period. Despite the recorded rise, the incidence rates for different sites of cancer (except for skin cancer) were significantly lower compared with their corresponding national rates for 2006. The results point to improvements in the cancer diagnosis and registry in the province, although real changes in cancer incidence over the period cannot be ruled out.

Augmentation apparente de l'incidence du cancer dans une petite province de la République islamique d'Iran : étude de cohorte populationnelle

RÉSUMÉ En 2006, le registre national du cancer iranien signalait qu'une petite province située dans le sud du pays, Kohgiluyeh et Boyer-Ahmad, avait une faible incidence pour presque tous les types de cancer. Dans une étude de cohorte populationnelle, les données concernant 660 cas de cancer dans la province de Kohgiluyeh et Boyer-Ahmad ont été analysées après nouvelle vérification des codes CIM et élimination des doublons. Entre 2007 et 2009, l'incidence moyenne annuelle pour tous les cancers a significativement augmenté, de 53,0 \% chez les hommes et de 115,1 \% chez les femmes. En revanche, le nombre de cancers de la prostate, de la thyroïde, de la vessie et des tissus mous a diminué au cours de la période de l'étude. En dépit de l'augmentation enregistrée, les taux d'incidence pour les différents sites de cancer (à l'exception du cancer de la peau) étaient significativement inférieurs aux taux nationaux correspondants en 2006. Les résultats semblent indiquer des améliorations du diagnostic du cancer et de son enregistrement dans la province, même si de véritables changements dans l'incidence du cancer sur la période en question ne peuvent être exclus. 


\section{Introduction}

According to national cancer statistics in the Islamic Republic of Iran, cancer is the third cause of death in the country (1) and, based on the same source of data, the incidence of cancer appears to be rising $(2,3)$. Cancer is therefore a serious health concern for the Iranian authorities and a proper and urgent response is required. The first crucial step in planning any national preventive and control programme is to develop an accurate and representative cancer monitoring and surveillance system to guide the prioritization of response $(4,5)$. As in most other countries, the Islamic Republic of Iran has a national cancer registry (NCR) which is responsible for providing data on cases of cancer $(6,7)$. The accuracy and completeness of the NCR data are considered crucial in research and interventions on cancer

The Iranian national health-care system essentially comprises 2 main sectors providing different levels of health and medical services under the supervision of the Iranian Ministry of Health and Medical Education (8). Primary health care, including vaccination, family planning and primary and general medical services, is provided free of charge or at low cost by the government for all rural and urban residents. Ideally, all Iranian citizens are registered and covered by this primary health-care network, especially for vaccination, child growth and development monitoring and maternal health services. Medical services, including medical diagnosis and treatment, are provided by the public and private sectors under the supervision of the Ministry of Health.

The Iranian NCR programme has been integrated into the Iranian national health-care system since 1984 and has been extended and improved continuously thereafter. In 1999, however, it was reported that the NCR was able to detect and record only $18 \%$ of expected cases. This figure improved dramatically to $81 \%$ in 2006 and since then the NCR has provided up-to-date and (arguably) representative epidemiological information on cancer at the national level (9). The improvements in the quality and completeness of the NCR database are due to the fact that NCR has become a part of the national health-care system and is fully supported by the Ministry of Health. Moreover, according to a bill passed by the Iranian Parliament, all private and public pathology and histology laboratories as well as hospitals are required to report all new cancer cases diagnosed and all cancer deaths to the NCR programme. In addition, according to the manual of the Iranian NCR programme, all cancer diagnoses need to be backed up with histology of biopsy specimens performed by pathology centres. Basic pathology and demographic information is extracted from the patients' files via a specially designed NCR data collection form. Although the pathology centres report cancer cases on a monthly base, provincial and national NCR offices take several years to complete the whole process of data collection, coding [based on International Classification of Diseases, version 9 (ICD 9) codes], entry and quality control. For example, a report on national cancer incidence and mortality for 2006 and details about the Iranian NCR programme were published in 2009 (1). As the NCR covers major sources of data on cancer throughout the country, it is generally believed that at the national level the programme detects as many cases of cancer as practically possible. The data provided by the NCR are therefore considered valuable and reliable for authorities and researchers who work on epidemiology and control of cancer (9).

An article published in 2009 and based on an official report from the Iranian NCR office showed that in 2006 Kohgiluyeh and Boyer-Ahmad province $(K \& B)$, a small province located in the southern part of the country, had a much lower incidence rate of almost all types of cancer compared with its neighbouring provinces and with national figures (1). Although certain environmental and social factors, including lower levels of environmental pollution and a more traditional lifestyle, may be used as justification for the lower incidence of specific types of cancer, the significantly lower incidence rates for all types of cancer in K\&B were not easily justifiable. This study aimed to estimate the basic epidemiological indices of cancer in $\mathrm{K} \& \mathrm{~B}$ for a 3-year period from year 2007 to 2009 using the same data sources and strategies as used by the NCR. This 3-year population-based cohort study estimated cancer incidence for the study period and compared the findings with the results of the official report of the NCR for the year 2006 (1).

\section{Methods}

\section{Data source}

$K \& B$ is a small province located in the mid-south of the Islamic Republic of Iran with a population of about 630000 (10). During the study period, the province had 7 pathology centres providing all pathology and histology tests throughout the province.

The data collection strategy for this study was similar to that of the NCR programme. Accordingly, from 2007 to 2009 the positive results of all pathology tests for cancer were collected from laboratory centres based in $K \& B$ province. The local cancer registry office normally takes about 2 years to collect and complete the required information from hospitals and laboratories. Therefore in 2012 all the registered cases during the study period were cross-checked for duplicates and only primary site cancers were retained in the data set for analysis. ICD codes were rechecked by an experienced coder to confirm the accuracy 
of the codes attached to the patient's information.

\section{Study population}

The study population was all cases reported to be residents of $K \& B$ at the time when pathology samples were taken. Information about the size and age and sex distribution of the $K \& B$ population during the study period was obtained from the official report of the Statistical Centre of Iran (10). Ethical approval for the study was obtained from the Yasuj University of Medical Sciences ethics committee.

\section{Analysis}

In order to avoid instability in the anatomical site-specific rates, sites with a small number of cases were merged as a group named "other". For the same reason, data for the whole study period (3 years) was divided by 3 to calculate the average annual incidence rate of cancer. Age-standardized rates (ASR) were used for comparing the local and national figures. Chi-squared and chisquared for trend tests were used for statistical analysis of distribution and trend of cancer in the population. Analysis was done using Microsoft Excel.

\section{Results}

Over the 3 year study period (2007-09), 660 eligible cases of cancer were reported to the K\&B NCR provincial office. The average annual ASR of all cancers was 64.58 per 100000 . The average annual sex-specific ASR for the province were 74.95 per 100000 and 45.85 per 100000 for men and women respectively. This was a significantly higher risk of cancer in males compared with females (relative risk $=1.69, P<0.01)($ Table 1$)$.

These figures are significantly higher than the K\&B provincial figures (50 per 100000 and 39 per 100000 for men and women respectively; $P<0.05$ ) reported by Mousavi et al. (1), based on the official report of NCR data for the year 2006 (1). In addition, a clear upward trend in the incidence of cancer was observed during the study period (Figure 1). Accordingly, from 2007 to 2009 the annual incidence rate of cancer increased on average by $53.0 \%$ and $115.1 \%$ in men and women respectively $(P<0.05)$. However, as shown in Figure 2 , the percentage change for different types of cancer during the study period were not similar $(P<0.05)$. This reveals that the incidence of brain and breast cancers had the highest percentage increase (450\% and $230 \%$ respectively) $(P<0.05)$, whereas the incidence of prostate, thyroid and soft tissues cancers were $27.3 \%, 10.0 \%$ and $8.0 \%$ lower respectively (although not significantly) during the same period $(P>0.05)$.

According to the cancer-specific incidence rates presented in Table 1, skin and stomach cancer in $K \& B$ were the most prevalent types of cancer (21.48 and 15.13 per 100000 in males and 15.06 and 4.84 per 100000 in females for skin and stomach cancer respectively), which is similar to the national figures (20.00 and 15.00 per 100000 in males and 13.44 and 6.89 per 100000 in females for skin and stomach cancer respectively) (Figure 3).

Age-specific rates of all types of cancer are presented in Figure 4. Although similar patterns was seen for the local and national figures, the age-specific incidence rates in $\mathrm{K} \& \mathrm{~B}$ province were predominantly lower than the corresponding national figures especially from ages 60 to 80 years.

\section{Discussion}

$\mathrm{K} \& \mathrm{~B}$ is a small and relatively economically deprived province located at the mid-south region of the Islamic Republic of Iran. Similar to the other parts of the country, residents of $K \& B$ have been experiencing major changes in several health-related factors, especially lifestyle, health care and age distribution of the population in recent years (10). Iranians are increasingly following the lifestyles of more industrialized countries, having easier access to better health-care services and experiencing a higher life expectancy. For example, the first fast-food restaurant was opened in K\&B's capital (Yasuj) in 1985, but the numbers of these rapidly rose to 172 in the year 2008 and are still rising. Moreover, during recent decades, as in other parts of the country, the quality of and access to the health and medical services provided by the public and private sectors have greatly increased. This has resulted in a significant improvement in the diagnosis and treatment of diseases including chronic conditions such as cancer $(1,9)$. The improvements in health and medical care have also had an impact on the NCR in recent years. For example, since 2006 all suspected cases of cancer are required to be confirmed by pathology and reported to the NCR on a monthly basis.

The results of the current 3-year population-based cohort study indicate a significant increase in the ASR of cancer from 2007 to 2009 compared with the corresponding rate for the year 2006 reported by Musavi et al. (1). Although we cannot completely rule out the possibility that there has been a dramatic increase in the incidence of cancer within this short period of time (due to changes in the lifestyle of the population and environmental factors, as mentioned earlier), this explanation is difficult to justify. A more convincing explanation for such a phenomenon would be improvements in the diagnosis and reporting of cancer cases during and after the transitional period of the national health-care system and the NCR programme. In other words, although according to researchers and national authorities, cancer is becoming more common in the Islamic Republic of Iran and will probably continue to do so, it is not clear whether the change in the incidence of different types of cancer is (at least) partly due to the 


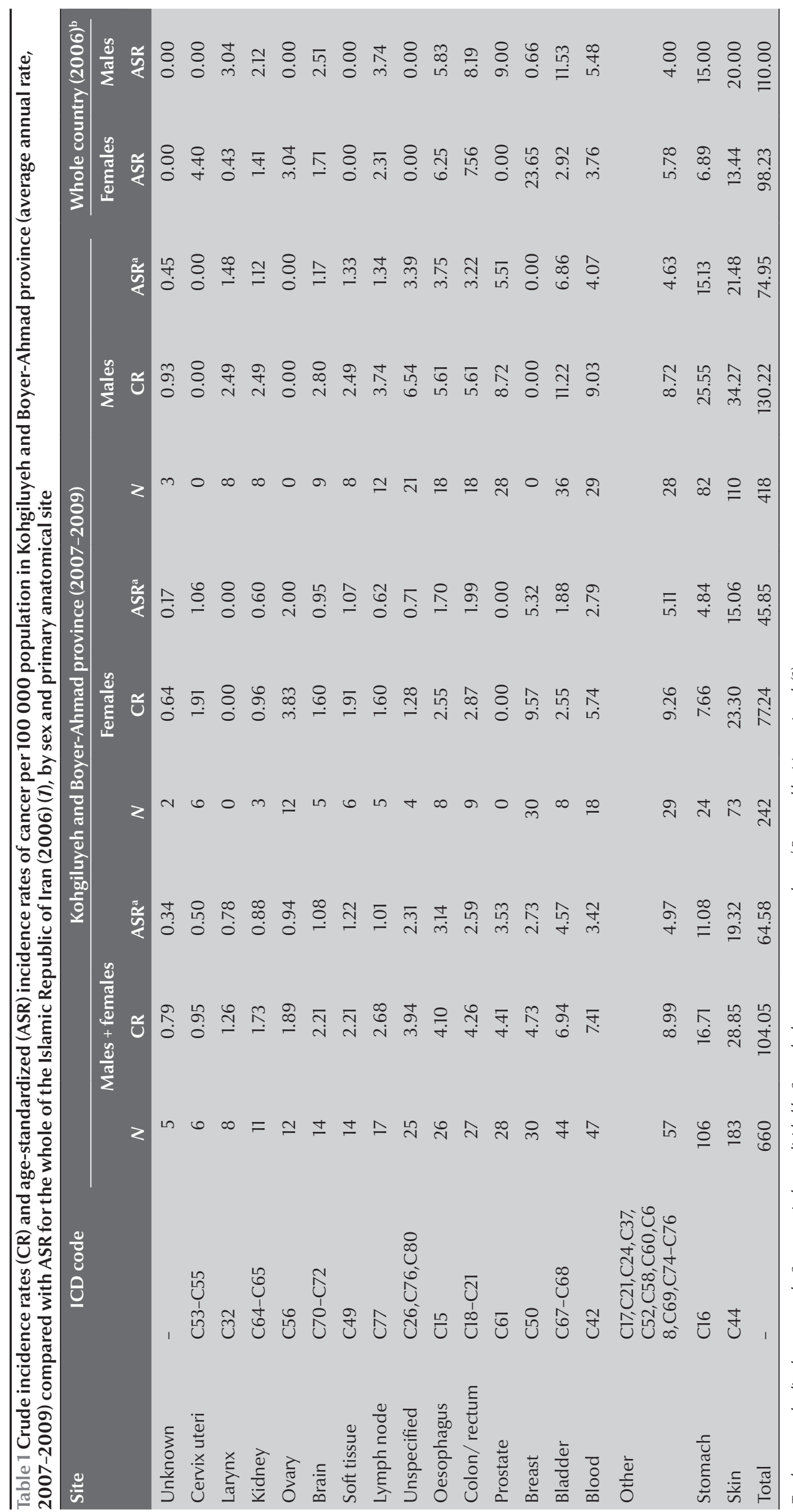




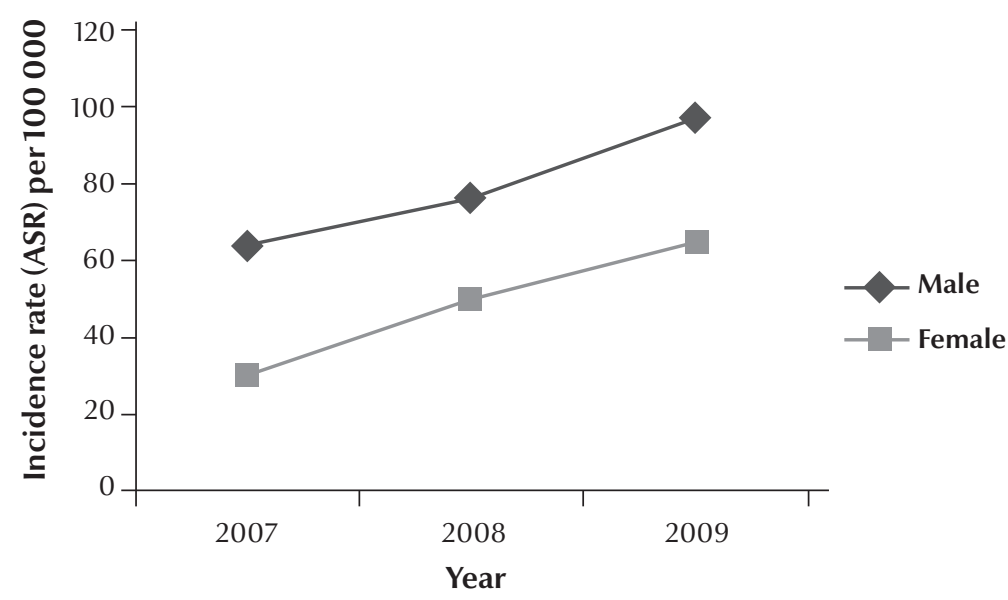

Figure 1 Annual age-standardized incidence rates (ASR) of cancer in Kohgiluyeh and Boyer-Ahmad province (2007-2009), by sex

improvement in the diagnosis and/ or registry of cancer cases (11). On the other hand, the dramatic rise in

cancer incidence in the Islamic Republic of Iran is not an isolated example, as according to a review article by El Saghir et al. most neighbouring Arab countries are reporting similar trends (12). Although their review mentioned the effect of improved cancer registration programmes on cancer epidemiology, the authors argued that these statistics represent the real status of cancer in Arab countries and that changing lifestyles including dietary habits, lack of exercise and urbanization were the main cause of the raising trend in cancer incidence.

According to the results of the current study, the incidence of all types of cancer (except skin cancer in both sexes and stomach cancer in males) were lower in $\mathrm{K} \& \mathrm{~B}$ than the corresponding national levels. However, a dramatic increase in the incidence of different types of cancer occurred for almost all

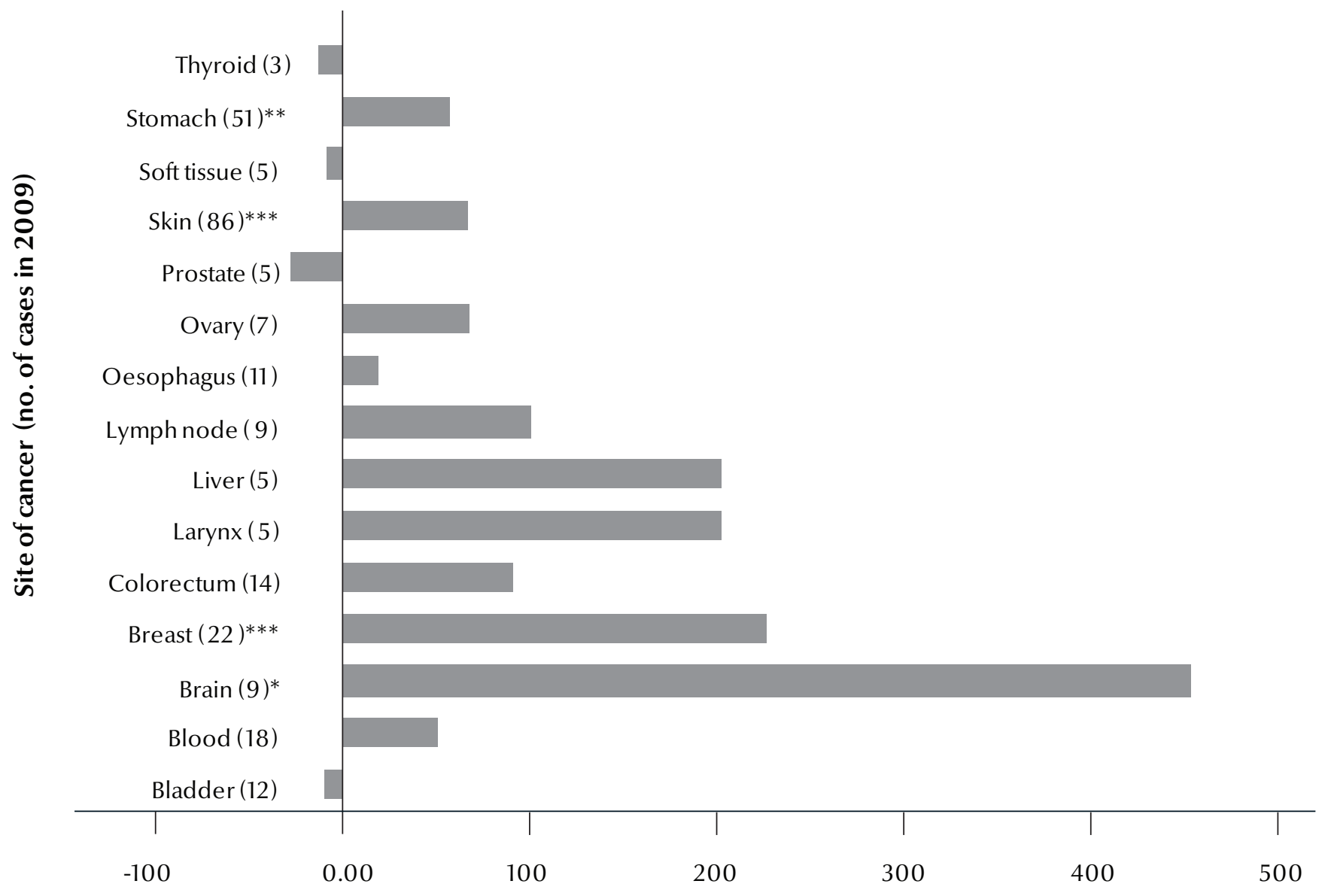

Rate of change from 2007 to 2009 (\%)

Figure 2 Rate of change in annual cancer incidence rates in Kohgiluyeh and Boyer-Ahmad province from 2007 to 2009, by anatomical site $\left({ }^{*} \boldsymbol{P}=<0.5,{ }^{* *} \boldsymbol{P}=<0.01,{ }^{* * *} \boldsymbol{P}=<0.001\right)$ 


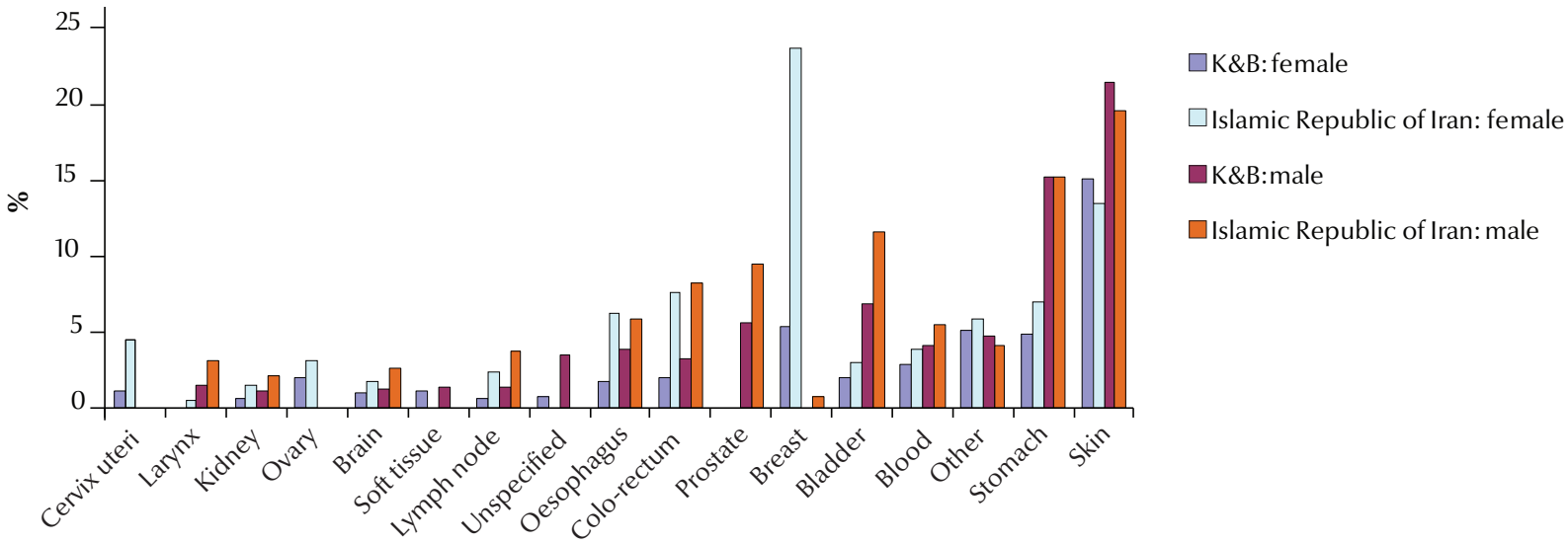

Figure 3 Comparison of age-standardized cancer incidence rates in Kohgiluyeh and Boyer-Ahmad (K+B) province (annual average rate, 2007-2009) and in the whole of the Islamic Republic of Iran (2006) (1), by primary anatomical site and sex

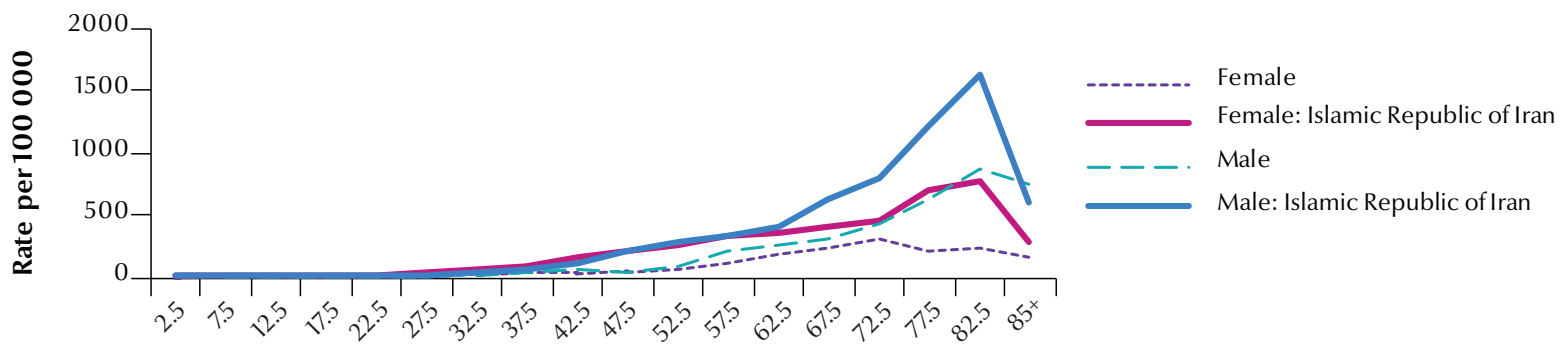

Age group (years)

Figure 4 Age-specific cancer incidence rates in Kohgiluyeh and Boyer-Ahmad province (average annual rate, 2007-2009)

types of cancer with completely different aetiologies. These results further point to an ongoing improvement in the quality and quantity of cancer reporting. However, it is important to note that the hypothesis of improvements to the cancer registry (which are also still ongoing) cannot fully explain the results. For example, the 5 most common types of cancer in $\mathrm{K} \& \mathrm{~B}$ province were not in accordance to the corresponding national figures (13) and the annual incidence rates of skin and stomach cancers in $\mathrm{K} \& \mathrm{~B}$ province during the study period (2007-2009) were higher compared with the corresponding national rates in 2006. Moreover, the rates of cancer of the prostate, soft tissues and thyroid decreased during the same period (although not significantly). This means that we need to argue that there has been a disproportionate registration for different sites of cancer. Whatever the reasons for the increases, the higher incidence of skin and stomach cancers in both males and females in $\mathrm{K} \& \mathrm{~B}$ province is concerning and needs an urgent response, including further studies to understand the epidemiology of these diseases.

The status and trend of cancer incidence in $\mathrm{K} \& \mathrm{~B}$ province, as a part of the NCR in Islamic Republic of Iran, may suggest that significant changes in the number and relative distribution of registered cases at the local and national levels are at least partly due to improvements in the diagnosis and reporting of cases (9). While the NCR programme in the country is taking major steps towards the improvement of the quality and quantity of the cancer registry, the data are to be used and interpreted carefully as there may be some concerns about the representativeness and reliability of the data. From a more general point of view, major international and local differences in the quality and coverage of cancer diagnosis and registry programmes exist (4). When conducting time-trend or national and international comparative studies we need careful consideration of the quality and stability of cancer registry programmes in the study populations 
as otherwise misleading results and interpretations may occur.

There were some limitations to the current study. As mentioned earlier, $K \& B$ was selected for the study because it reportedly had one of the lowest rates of cancer in the country. The province has a relatively small population and therefore a limited number of cancer cases was expected to have occurred during the study period.
However, power calculation showed that the number of reported cases was big enough to provide sufficient power (80\%) in finding a significant difference in the rate of change in common types of cancer in the study population or of finding a significant time trend in the cancer rate (the most important findings), as found in this study. As with many other similar studies using data from NCR programmes, despite all possible measures taken to detect and correct such errors in the data, errors in recorded address and date of diagnosis of the patients could not be ruled out.

\section{Acknowledgements}

Funding: This study was funded by Yasuj University of Medical Sciences

Competing interests: None declared.

\section{References}

1. Mousavi SM, Gouya MM, Ramazani R, Davanlou M, Hajsadeghi N, Seddighi Z. Cancer incidence and mortality in Iran. Ann Oncol. 2009 Mar;20(3):556-63. PMID:19073863

2. Malekzadeh R, Bishehsari F, Mahdavinia M, Ansari R. Epidemiology and molecular genetics of colorectal cancer in Iran: a review. Arch Iran Med. 2009 Mar;12(2):161-9. PMID:19249887

3. Babaei $\mathrm{M}$, et al. Cancer incidence and mortality in Ardabil: report of an ongoing population-based cancer registry in Iran, 2004-2006. Iran J Public Health. 2009;38(4).

4. Ferlay J, Shin HR, Bray F, Forman D, Mathers C, Parkin DM. Estimates of worldwide burden of cancer in 2008: GLOBOCAN 2008. Int J Cancer. 2010 Dec 15;127(12):2893-917. PMID:21351269

5. Bradley CJ, Luo Z, Given CW. Cancer incidence in elderly Medicare and dually eligible beneficiaries. Health Serv Res. 2008 Oct;43(5 Pt 1):1768-79. PMID:18479409

6. Parkin DM, Bray F. Evaluation of data quality in the cancer registry: principles and methods Part II. Completeness. EurJ Cancer. 2009 Mar;45(5):756-64.PMID:19128954.
7. Gjerstorff ML. The Danish Cancer Registry. Scand J Public Health. 2011 Jul;39(7) Suppl:42-5. PMID:21775350

8. Mehrdad R. Health system in Iran. Japan Med Assoc J. 2009;52(1):69-73 (http://www.med.or.jp/english/ pdf/2009_01/069_073.pdf, accessed 30 March 2015).

9. Etemadi A, Sadjadi A, Semnani S, Nouraie SM, Khademi H, Bahadori M. Cancer registry in Iran: a brief overview. Arch Iran Med. 2008 Sep;11(5):577-80. PMID:18759534

10. Official report on Iranian census. Tehran: Statistical Center of Iran; 2011 [in Farsi].

11. Sadjadi A, Nouraie M, Ghorbani A, Alimohammadian M, Malekzadeh R. Epidemiology of breast cancer in the Islamic Republic of Iran: first results from a population-based cancer registry. East Mediterr Health J. 2009 Nov-Dec;15(6):1426-31. PMID:20218134

12. El Saghir NS, Khalil MK, Eid T, El Kinge AR, Charafeddine M, Geara F, et al. Trends in epidemiology and management of breast cancer in developing Arab countries: a literature and registry analysis. Int J Surg. 2007 Aug;5(4):225-33. PMID:17660128 